\title{
Taxation on ultra-processed foods to trim obesity: Is it plausible in Canada?
}

\author{
Dana Hankinson \\ Department of Psychology, University of Alberta, Edmonton, Alberta \\ Corresponding author: drhankin@ualberta.ca
}

\section{ABSTRACT}

As the prevalence of excess body weight has become normalized ${ }^{1}$ in Canadian society, this paper argues for implementation of a sugar-sweetened beverages (SSB) and high saturated fat (SF) food taxation in Canada. These harmful foods and beverages are associated with excess calorie intake, lower nutrient intake, and a rise in body mass index. As the waistlines of Canadians continue to grow, it is of utmost importance for obesity and overweight to be externally managed by the government with taxation on unhealthy substances, and a simultaneous subsidy on healthier alternatives. Potentially pairing SSB/SF taxation with a fruits and vegetables subsidy could be one of the most effective means of achieving altered consumption patterns. The purpose is to curb availability of the former, increase consumption of the latter, and reduce weight gain and the harms that come along with it (e.g. metabolic disease and type II diabetes). The paper's analysis focuses on children, adolescents (12-17 years old), and lower socioeconomic status populations, as these populations are at a higher risk for overweight and obesity and would be most positively affected by the proposed taxation and subsidy. Briefly outlining the options governments have in reducing the levels of SSB/SF, questions are posed for future research regarding the area of ultra-processed food taxations. Finally, notable objections to SSB/SF taxation are considered and alternative methods are suggested such as income-based subsidy programs, which address inequitable distributions of proposed taxation on vulnerable groups like children, adolescents, and lower socioeconomic status groups.

\section{Introduction}

It is well documented that convenience comes with increased calories, unnecessary fats, sugars, and refined carbohydrates that are strongly correlated with increased levels of overweight and obesity (Moubarac et al., 2014). It is also known that certain social determinants of health like lower socioeconomic status ${ }^{2}$ and educational level correlate strongly with buying more ultra- 
processed, ready-to-eat foods, which tend to be cheaper than healthier alternatives (Monteiro et al., 2017). This is because ultra-processed foods, per the United Nation's Nova food classification system, are "not modified foods, but formulations made mostly or entirely from substances derived from foods and additives, with little if any intact [unprocessed or minimally processed foods]" (Monteiro et al., 2017, p. 9; Moubarac et al., 2014). Further, ultra-processed foods are often sugared, lack nutrients, are energy dense, and include more salt, sugars, fats, and oils than unprocessed foods (Monteiro et al., 2017; Moubarac, Batal, Louzada, Steele, \& Monteiro, 2017; Moubarac et al., 2014).

Canadian longitudinal data on the prevalence of obesity help to establish growing norms and how they have been shaped over time (i.e. how overweight and obesity have become seminormalized in North American society). For instance, there has been a 200 percent increase in the prevalence of obesity in Canada since 1985 with provincial rates ranging from 20 to 35 percent and a national average of 25 percent (OECD, 2014). The highest increases in obesity have occurred in classes II and II $^{3}$ (Twells, Gregory, Reddigan, \& Midodzi, 2014), with nearly 60 percent of Canadian adults and one-third of children and adolescents overweight or obese (Duhaney et al., 2015). Further, current data show nearly 1 in 7 Canadian children are exclusively obese (Rao et al., 2016). This alarming rise in obesity rates over the past 40 years can largely be attributed to unhealthy diets coupled with sedentary lifestyles (Duhaney et al., 2015). It is safe to say the prevalence of excess body weight has become normalized in Canadian society, made clear by the fact that the average body mass index sits in the overweight category at $26-27 \mathrm{~kg} / \mathrm{m}^{2}$ (Ogilvie \& Eggleton, 2016).

Research has abundantly shown that obesity is linked to numerous comorbidities such as metabolic disease, coronary heart disease, type Il diabetes, and sleep apnea (Haslam, 2007;
Ogilvie \& Eggleton, 2016). Approximately four billion dollars (2.7 percent) of the total Canadian healthcare budget is spent on obesity-related illnesses, such as high blood pressure, high cholesterol, type II diabetes, and heart attacks (Anis et al., 2010). As this figure does not include the loss of work productivity, it is reasonable to assume obesity's total cost to society is much larger than the figure presented. Thus, it is of utmost importance for obesity and overweight to be regulated through immediate implementation of a tax on unhealthy substances, along with a simultaneous subsidy on healthier alternatives.

To explore this concept, I conducted a literature review specifically focused on the Canadian context, while drawing upon other countries' successes and failures in implementing a tax on sugar-sweetened beverages (SSB) and foods high in fats. As both saturated and trans fats are contributing factors in the increased levels of overweight and obesity through the consumption of ultra-processed foods, saturated fats (SF) are solely focused on throughout the literature review because research is more established, and a successful taxation of SF could act as a gateway into the worse-for-you trans fats. Whereas other articles of this nature have solely focused on taxation, this paper focuses on a comprehensive strategy combining both taxation and subsidy incentives. This unique combination of tax and subsidy alleviates the oppositional views claiming SSB/SF taxation will disproportionately harm already marginalized groups such as children, adolescents, and lower socioeconomic groups who are at an elevated risk of overweight and obesity.

\section{"Fat tax" - what is it?}

Taxation of overly-processed foods, typically called a 'fat tax' or 'sugar tax,' includes unhealthy commodities such as SSB, foods high in SF, and other ultra-processed foods. These foods are purposefully designed to hit a literal 'sweet spot' in consumers' mouths and brains, so much so that 
they can lead to habit-forming and quasi-addictive consumption, making healthy food choices more difficult to select (Millar, 2013; Monteiro et al., 2017; Moss, 2014). These products are consistently shown to be associated with excess calorie intake, lower nutrient intake, lower overall diet quality (Wang et al., 2015), and a rise in body mass index (Maniadakis, Kapaki, Damianidi, \& Kourlaba, 2013; Sturm, Powell, Chriqui, \& Chaloupka, 2010). The addictive combination of salt, sugar, and fat in ultra-processed foods have clearly done their jobs as Canadian household food purchases since 1938 have shifted from predominantly unprocessed foods to ultra-processed foods (Moubarac et al., 2014).

To implement taxation on ultra-processed foods, particularly SSB and SF, Canadian law-makers and health practitioners will have to learn from previous failed taxes like Denmark's. In October 2011, Denmark introduced the world's first 'fat tax' to curb obesity and related comorbidities such as cardiovascular disease (Franck, Grandi, \& Eisenberg, 2013). Unfortunately, because of the ease of travel between surrounding countries, citizens of Denmark found a way around the newfound tax: shop outside of the country. Because of this, the Danish government - to the food corporations' and citizens' delight - repealed the tax 15 months after its implementation (Bødker, Pisinger, Toft, \& Jørgensen, 2015). The defeat of the world's first 'fat tax' was a tough loss for health advocates around the world, especially in Canada, because unhealthy diets are one of the leading causes of death, disability, and years of life lost in this country (Duhaney et al., 2015).

The main directive of SSB/SF taxation and a fruits and vegetables subsidy is to curb availability of the former, increase consumption of the latter, and reduce unhealthy weight gain (Lustig, Schmidt, \& Brindis, 2012; Sturm et al., 2010). When obesity initially presented itself as a confounding variable associated with numerous negative health implications in the 1970's, medical personnel and academics alike believed SF were to blame. This created what was known as the 'fat-free' craze the largest food frenzy of the twentieth century. However, when fat was reduced or eliminated from a product, sugar and other additives were added to keep the flavour and texture the same. It turns out; however, fat was not the main issue because the waistlines of North Americans continued to grow during this time - a lot. Today, most of the medical community has transitioned from thinking fat was the sole issue, to realizing sugar, particularly fructose, is one of the main adversaries in the battle against obesity, thus, furthering the need for a taxation on both substances (Lustig et al., 2012).

\section{Canadian taxation on ultra- processed foods}

As of late, there is no Canada-wide approach to curb obesity, although some have been proposed, such as a national educational awareness campaign and an overhauling of Canada's Food Guide (Ogilvie \& Eggleton, 2016). Thus, a nationwide SSB and SF tax would be the first of its kind in the country. Moubarac et al. (2017) found that in 2004 ultra-processed foods constituted nearly half of daily calories consumed by Canadians 2 years and older. Further, there was disparity within the country, with less educated individuals, those living in rural areas (both factors in determining lower socioeconomic status), and children and adolescents (of all socioeconomic groups) consuming significantly higher amounts of ultra-processed foods than their counterparts (Moubarac et al., 2017).

As tackling an entire population is beyond the scope of this paper, I focus on children and adolescents and lower socioeconomic status populations in my literature review. This is not to say that population-wide dietary taxation is unnecessary, quite the opposite in fact, but as individual and population-level factors are 
intertwined, these two sub-groups will be most impacted by SSB/SF taxation and a fruits and vegetables subsidy (Moodie et al., 2013). Of the options available to governments (e.g. an outright prohibition, corporate self-regulation), pairing SSB/SF taxation with a fruits and vegetables subsidy is shown to be the most effective means of achieving altered consumption patterns (Buhler, Raine, Arango, Pellerin, \& Neary, 2013; Niebylski, Redburn, Duhaney, \& Campbell, 2015). Implementation, however, is only the first part of the solution: a key component of successful SSB/ SF taxation is to use the revenue ${ }^{4}$ to finance the fruits and vegetables subsidy program and regain lost medical costs attributed to obesity. I see this as the only way the public would be supportive of such hefty taxation. For a taxation and subsidy program like this to work, government agencies must be focused on reducing consumption levels, and not the potential profit generated from such initiatives (Bødker et al., 2015)

To reduce consumption levels of unhealthy ultra-processed foods, several studies reviewed different taxation levels to see the size and strength of any effects (Franck et al., 2013). A systematic review conducted by Niebylski et al. (2015) found a minimal 10-15 percent tax/subsidy would be effective in achieving beneficial health effects. Similarly, Sturm et al. (2010) showed that a low SSB taxation of up to 7 percent was ineffective for reducing total consumption of SSB and obesity rates in elementary students. An alternative to subsidizing fruits and vegetables is to subsidize specific nutrients instead of the food groups as a whole ${ }^{5}$ (e.g. fructose, saturated fats; Franck et al., 2013; Thow, Jan, Leeder, \& Swinburn, 2010). However, the question of who the tax gets directed to comes up. Does the government tax the food corporations and then the corporations redistribute the tax among their commodities (i.e. excise), or will the tax be directly placed on the food items (i.e. sales tax)? Although these are interesting concerns, the logistics of policy implementation go beyond the scope of this paper and should be relegated to future research to determine the best method of application.

\section{Oppositional view of taxation}

Opponents of SSB/SF taxation argue that such taxes will disproportionately harm lower socioeconomic status groups who overwhelmingly consume these high-fat, high-sugar, and overlyprocessed foods. Additionally, consumption taxes can have regressive effects by targeting the already vulnerable children, adolescents, and lower socioeconomic status groups (Buhler et al., 2013; Maniadakis et al., 2013; Thow et al., 2010). This position may advocate for a subsidy that is income-based, where only those below the poverty level are awarded cost-saving measures.

However, a study conducted by Sturm et al. (2010) found a modest taxation (7 percent) lowered SSB intake by children from lower socioeconomic backgrounds in the U.S.A. (It is worth noting that this study found a 7 percent taxation reduced SSB intake only in children from lower socioeconomic statuses, not the entire population of elementary children studied.) Even though 7 percent is well below the 10-15 percent taxation suggested by Niebylski et al. (2015), it showed benefits for groups vulnerable to obesity. This points some evidence towards SSB/SF taxation being more readily implemented for groups that are at a greater risk for obesity and its comorbidities, namely, lower socioeconomic status groups, children, and adolescents (Andreyeva et al., 2011). Nonetheless, a subsidy program that is income based could alleviate consumption of unhealthy foods in lower socioeconomic status groups but would do nothing to divert other socioeconomic groups from choosing healthier alternatives. As obesity is an issue spanning all ethnicities, genders, and socioeconomic statuses in Canada, subsidy initiatives should be distributed equally among the population 
for those who wish to utilize the programs.

Building off an income-based tax and subsidy program, another way it could be implemented is by combining income-based and province-based. Twells et al. (2014) took 2011 provincial rates of overweight and obesity and noted a stark contrast in obesity levels between Western and Eastern provinces. Specifically, the average prevalence of obesity in the three most Western provinces, British Columbia, Alberta, and Saskatchewan, is 18.63 percent $(14.5,19.3$, and 22.1 percent, respectively; Twells et al., 2014). Conversely, the average prevalence of obesity for the three most Eastern provinces, Newfoundland, Prince Edward Island, and Nova Scotia is 24.97 percent $(27.7,23.5$, and 23.7 percent, respectively). These unequal rates of obesity across Canada clearly show that levels are higher in the East and lower in the West, but why? Differing provincial obesity levels can be attributed to a multitude of causes including social class, levels of income, and rural versus urban living (Twells et al., 2014). Just as obesity levels are unequal in Canada, so too are provincial taxes. Because a taxation on SSB/SF would most likely fall to provincial governments to pay for and administer, opponents worry that provinces with lower rates of obesity may not reallocate funds in obesity-treatment and prevention avenues (Buhler et al., 2013) ${ }^{6}$. This raises a valid concern regarding inequitable distributions of a proposed taxation.

Another key opposition to taxation of ultraprocessed foods is that a 'nanny state' would ensue, where governments control substantial portions of its citizens' behaviours and restrict their consumption choices (Buhler et al., 2013). Because of this, consumers may engage in adverse substitution effects like other SSB/SF substances or jurisdictions (as happened in Denmark) that may be worse than the original commodities (Bødker et al., 2015). My rebuttal to this valid concern is that having government recognition (via subsidies and taxation) shows that the health of current and future populations is an important priority for policy makers (Olstad et al., 2017). Another way of looking at government intervention is that it is the government's responsibility to protect the public's health from harmful substances, most of which are produced by multi-national conglomerates (Moodie et al., 2013). Nonetheless, there exist substantial conflicts of interest between the food corporations producing ultra-processed foods and the governments tasked with regulating said products.

\section{Final remarks}

Like tobacco, alcohol, and seat belt use, SSB/ SF taxation will likely only be implemented after numerous failures of the corresponding industries to problem-solve via self-regulation (Moodie et al., 2013). As a society, however, we desperately need to halt the comorbidities that arise from the overconsumption of SSB and SF. This is especially true in children and adolescents; whose diets compose of up to 55 percent ultra-processed foods (Moubarac et al., 2017) with 10 to 15 percent of calorie intake coming from SSB (Franck et al., 2013). Because of the staggering data, the need for an immediate nation-wide governmental taxation is evident, despite data about the use of taxes to curb consumption of SSB/SF being in its infancy.

Although there are both positives and negatives for a proposed taxation in Canada, there is by no means a consensus on the topic in public, academic, and healthcare settings. As with the implementation of GST in 1991, Canadians will be resistant to a SSB/SF taxation, however, this too can subside and become integrated into society. As can be seen from the failed Danish fat-tax that lasted a mere 15 months, food corporations are resistant and willing to take legal action against governments that impose restrictions on their consumers (Bødker et al., 2015). With diets that are notorious for failing and convenient food options that are laced in bad sugars and fats, the hurdles experienced in implementing a SSB/ 
SF taxation and fruits and vegetables subsidy will steadily rise along with the waistlines of Canadians unless direct action is taken. 


\section{Notes}

1. The word "normalized" is commonly used by Sociologists. So common, in fact, they do not feel the need to define it. The origin of the word, per the Dictionary of Sociology, in the Deviance Disavowal section, states: "[t]he concept was originally developed with reference to so-called social deviants, such as the physically handicapped, who had a strong interest in attempting to minimize the stigma of deviance in order either to appear normal or to normalize their interactions and relationships with the able-bodied. It is now used more widely, notably within the labelling perspective, to apply to all forms of deviant behaviour." The latter part of the definition is what I am referring to - obesity as a deviant characteristic that has become normal in society (up to a point), based on the constantly rising obesity rates in Canada.

2. Socioeconomic status is one's social position in society and is indicated by three intertwined factors; education, income, and occupation. Lower socioeconomic status is linked with health in many areas including decreased life expectancy, increased infant mortality rate, and increased risk of chronic diseases like lung cancer and alcoholism (Canadian Institute for Health Information, 2008).

3. The general breakdown of body mass index in bariatrics is as follows: Underweight $<18.5 \mathrm{~kg} / \mathrm{m}^{2}$, Normal $18.5-24.9 \mathrm{~kg} / \mathrm{m}^{2}$, Overweight $25.0-29.9 \mathrm{~kg} / \mathrm{m}^{2}$, Obese class I $30.0-34.9 \mathrm{~kg} / \mathrm{m}^{2}$, Obese class II $35.0-$ $39.9 \mathrm{~kg} / \mathrm{m}^{2}$, Obese class III 40.0-49.9 kg/m², and recently, super Obesity $\geq 50.0 \mathrm{~kg} / \mathrm{m}^{2}$.

4. It is worth noting that Andreyeva, Chaloupka, and Brownell (2011) devised a method of estimating revenues from an excise tax on SSB/SF that can be implemented in Canada as the calculation method would be near identical.

5. Thank you to the copyeditor for notifying me of an oppositional view to subsidizing specific nutrients: Michael Pollan's book, In Defense of Food argues against nutrient-specific dietary advice.

6. Further research should be conducted investigating the link between higher provincial tax rates and elevated levels of obesity in Eastern provinces like Newfoundland, PEI, and Nova Scotia. These provinces have 15 percent HST and some of the highest levels of obesity in the country, is this merely coincidence? 


\section{References}

Andreyeva, T., Chaloupka, F. J., \& Brownell, K. D. (2011). Estimating the potential of taxes on sugar-sweetened beverage to reduce consumption and generate revenue. Preventative Medicine, 52, 413-416. https://doi.org/10.1016/j.ypmed.2011.03.013

Anis, A. H., Zhang, W., Bansback, N., Guh, D. P., Amarsi, Z., \& Birmingham, C. L. (2010). Obesity and overweight in Canada: An updated cost-of-illness study. Obesity, 11, 31-40. https://doi.org/10.1111/j.1467-789x.2009.00579.x

Bødker, M., Pisinger, C., Toft, U., \& Jørgensen, T. (2015). The rise and fall of the world's first fat tax. Health Policy, 119, 737-742. https://doi.org/10.1016/j.healthpol.2015.03.003

Buhler, S., Raine, K. D., Arango, M., Pellerin, S., \& Neary, N. E. (2013). Building a strategy for obesity prevention one piece at a time: The case of sugar-sweetened beverage taxation. Canadian Journal of Diabetes, 37, 97-102. https://doi.org/10.1016/j.jcjd.2013.03.025

Canadian Institute for Health Information. (2008). Reducing gaps in health: A focus on socio-economic status in urban Canada. Ottawa, ON: CIHI. Retrieved from https://secure.cihi.ca/free_products/ Reducing_Gaps_in_Health_Report_EN_081009.pdf

Duhaney, T., Campbell, N., Niebylski, M. L., Kaczorowski, J., Tsuyuki, R. T., Willis, K., ... Ashley, L. (2015). Death by diet: The role of food pricing interventions as a public policy response and health advocacy opportunity. Canadian Journal of Cardiology, 31, 112-116. https://doi.org/10.1016/j. cjca.2014.09.005

Franck, C., Grandi, S. M., \& Eisenberg, M. J. (2013). Taxing junk food to counter obesity. American Journal of Public Health, 103, 1949-1953. https://doi.org/10.2105/ajph.2013.301279

Haslam, D. (2007). Obesity: a medical history. Obesity Reviews, 8, 31-36. https://doi.org/10.1111/j.1467-789x.2007.00314.x

Lustig, R. H., Schmidt, L. A., \& Brindis, C. D. (2012). The toxic truth about sugar. Nature, 482, 27-29. https://doi.org/10.1038/482027a

Maniadakis, N., Kapaki, V., Damianidi, L., \& Kourlaba, G. (2013). A systematic review of the effectiveness of taxes on nonalcoholic beverages and high-in-fat foods as a means to prevent obesity trends. ClinicoEconomics and Outcomes Research, 5, 519-543. https://doi.org/10.2147/ ceor.s49659

Millar, J. S. (2013). The corporate determinants of health: How big business affects our health, and the need for government action! Canadian Journal of Public Health, 104, e327-e329. Retrieved from http://www.jstor.org/stable/canajpublheal.104.4.e327

Monteiro, C. A., Cannon, G., Moubarac, J. C., Levy, R. B., Louzada, M. L. C., \& Jaime, P. C. (2017). The UN decade of nutrition, the NOVA food classification and the trouble with ultra-processing. Public Health Nutrition, 21, 5-17. https://doi.org/10.1017/s1368980017000234

Moodie, R., Stuckler, D., Monteiro, C., Sheron, N., Neal, B., Thamarangsi, T., Lincoln, P., \& Casswell, S. (2013). Profits and pandemics: Prevention of harmful effects of tobacco, alcohol, and ultraprocessed food and drink industries. Lancet, 381, 670-679. https://doi.org/10.1016/s0140$\underline{6736(12) 62089-3}$

Moss, M. (2014). Salt sugar fat: How the food giants hooked us. Toronto, ON: Signal

Moubarac, J. C., Batal, M., Louzada, M. L., Steele, E. M., \& Monteiro, C. A. (2017). Consumption of ultra-processed foods predicts diet quality in Canada. Appetite, 108, 512-520. https://doi. org/10.1016/j.appet.2016.11.006

Moubarac, J. C., Batal, M., Martins, A. P., Claro, R., Levy, R. B., Cannon, G., \& Monteiro, C. (2014). 
Processed and ultra-processed food products: Consumption trends in Canada from 1938 to 2011. Canadian Journal of Dietetic Practice and Research, 75, 15-21. https://doi. org/10.3148/75.1.2014.15

Niebylski, M. L., Redburn, K. A., Duhaney, T., \& Campbell, N. R. (2015). Healthy food subsidies and unhealthy food taxation: A systematic review of the evidence. Nutrition, 31, 787795. https://doi.org/10.1016/j.nut.2014.12.010

OECD. (2014). Obesity update. Retrieved from http://www.oecd.org/health/Obesity-Update-2014.pdf Ogilvie, K. K., \& Eggleton, A. (2016). Obesity in Canada: A whole-of-study approach for a healthier Canada. Report of the Standing Senate Committee on Social Affairs, Science and Technology. 1-48. Retrieved from https://sencanada.ca/content/sen/committee/421/SOCl/ Reports/2016-02-25_Revised_report_Obesity_in_Canada_e.pdf

Olstad, D. L., Ancilotto, R., Teychenne, M., Minaker, L. M., Taber, D. R., Raine, K. D., Nykiforuk, C. I. J., \& Ball, K. (2017). Can targeted policies reduce obesity and improve obesityrelated behaviours in socioeconomically disadvantaged populations? A systematic review. Obesity Reviews, 18, 791-807. https://doi.org/10.1111/obr.12546

Rao, D. P., Kropac, E., Do, M. T., Roberts, K. C., \& Jayaraman, G. C. (2016). Childhood overweight and obesity trends in Canada. Health Promotion and Chronic Disease Prevention in Canada, 36, 194198. https://doi.org/10.24095/hpcdp.36.9.03

Sturm, R., Powell, L. M., Chriqui, J. F., \& Chaloupka, F. J. (2010). Soda taxes, soft drink consumption, and children's body mass index. Health Affairs, 29, 1-7. https://doi.org/10.1377/ hlthaff.2009.0061

Thow, A. M., Jan, S., Leeder, S., \& Swinburn, B. (2010). The effect of fiscal policy on diet, obesity and chronic disease: A systematic review. Bulletin of the World Health Organization, 88, 609-614. https://doi.org/10.2471/blt.09.070987

Twells, L. K., Gregory, D. M., Reddigan, J., \& Midodzi, W. K. (2014). Current and predicted prevalence of obesity in Canada: A trend analysis. Canadian Medical Association Journal Open, 2, E18-E26. https://doi.org/10.9778/cmajo.20130016

Wang, J. W., Shang, L., Light, K., O'Loughlin, J., Paradis, G., \& Gray-Donald, K. (2015). Associations between added sugar (solid vs. liquid) intakes, diet quality, and adiposity indicators in Canadian children. Applied Physiology, Nutrition, and Metabolism, 40, 835-841.

https://doi.org/10.1139/apnm-2014-0447 